\title{
IMPlicATIONS OF High Dissolved Organic Matter Concentrations for OCEANic Properties and Processes
}

\author{
By George A. Jackson
}

$\mathrm{I}_{\mathrm{T}}$ of reduced oceanic nitrogen and carbon may be overlooked by traditional techniques used to measure dissolved organic carbon (DOC) and dissolved organic nitrogen (DON). Suzuki et al. (1985) and Sugimura and Suzuki (1988) have reported that concentrations of DOC and DON in the ocean are 2 to 5 times those measured with previous techniques. Williams and Druffel (1988) have discussed the measurement issues and their implications for the nature of dissolved organic carbon in the sea. In this article. some of the implications of the new DOC and DON values for oceanic biology and chemistry are examined.

\section{Traditional View of Elemental Cycling}

Organisms govern elemental distributions in the ocean because they concentrate chemical species from solution into particles. Particles, by virtue of their passive or active transport, can move their contents separately from that of the surrounding water. By forming near the surface and dissolving in deeper water, particles maintain concentration gradients in the ocean that mixing processes work to homogenize. Such particle-driven cycling has been invoked to explain the vertical and horizontal distributions of nitrogen. oxygen, phosphorus, carbon, silicon. cadmium, zinc and nickel, as well as other elements involved in biological processes. The photosynthetic requirement for light constrains most formation of bioparticles to the $50-100 \mathrm{~m}$ nearest the ocean surface. Patterns of vertical particle fluxes and distributions of elemental concentrations suggest that most biomatter is consumed and transformed back to inorganic forms within $300-400 \mathrm{~m}$ of the surface. Changes in nutrient concentrations between $400 \mathrm{~m}$ and the ocean bottom are relatively small.

A particularly striking result of biological cycling is the network of linear relationships between concentrations of dissolved nutrients. Redfield (1934) reported concentration ratios between $\mathrm{P}: \mathrm{N}: \mathrm{C}:-\mathrm{O}_{2}$ equal to 1:16:106:138 for the North Atlantic, and he noted the similarity of the ratios of changes in dissolved concentrations to the elemental ratios in bio-

George A. Jackson. Institute of Marine Resenorees. Srripps Institution of Oceanography. La Jolla. CA 92093. particles. Nitrate and phosphate are classically the dominant dissolved forms of fixed $\mathrm{N}$ and $\mathrm{P}$ in the ocean.

More extensive collections of data. including that of the Geosecs program (Craig $c t$ al. 1981), show that the relationship between the concentrations of nitrate and phosphate is remarkably linear, with two exceptions. First, in regions where anoxia leads to consumption of nitrate in the oxidation of organic matter, the phosphate concentration increases with no corresponding increase in nitrate concentration. This happens for phosphate concentrations greater than about $2.5 \mu \mathrm{M}$ in some areas of the Indian and Pacific Oceans, for example. Unfortunately, the eastern Pacific region, where extensive denitrification occurs, was not sampled as part of Geosecs.

Second. nitrate concentrations vanish at low concentrations of phosphate. leaving measurable phosphate without measurable nitrate. As a result, phosphate concentration varies while that of nitrate does not in regions traditionally described as nutrientstarved because of low nitrate concentrations. The near-surface region where the linear relationship between nitrate and phosphate fails is particularly important, because it is the region where much biological uptake occurs. For example, $35 \%$ of the plant growth in the Southern California Bight (and therefore $35 \%$ of the removal of nutrients from solution) occurs in water with less than $0.1 \mu \mathrm{M}$ nitrate: however. $25 \%$ of the growth occurs in water with phosphate concentrations in the range of 0.3 and $0.4 \mu \mathrm{M}$ (Fig. 1, p. 29). The fact that uptake occurs over such a small range emphasizes that changes over most of the nitrate and phosphate concentration range involve the remineralization of particles, not their formation.

There are three ways that concentrations of a chemical species and their concentration ratios can change in a volume of water. First, mixing with another water volume can smooth concentration variations, decreasing the large gradients found in the ocean. Second, chemical transformation from one to another form can occur: an example is the removal of nitrate and phosphate from solution by phytoplankton to form dissolved and particulate organic nitrogen and phosphorus compounds. While 


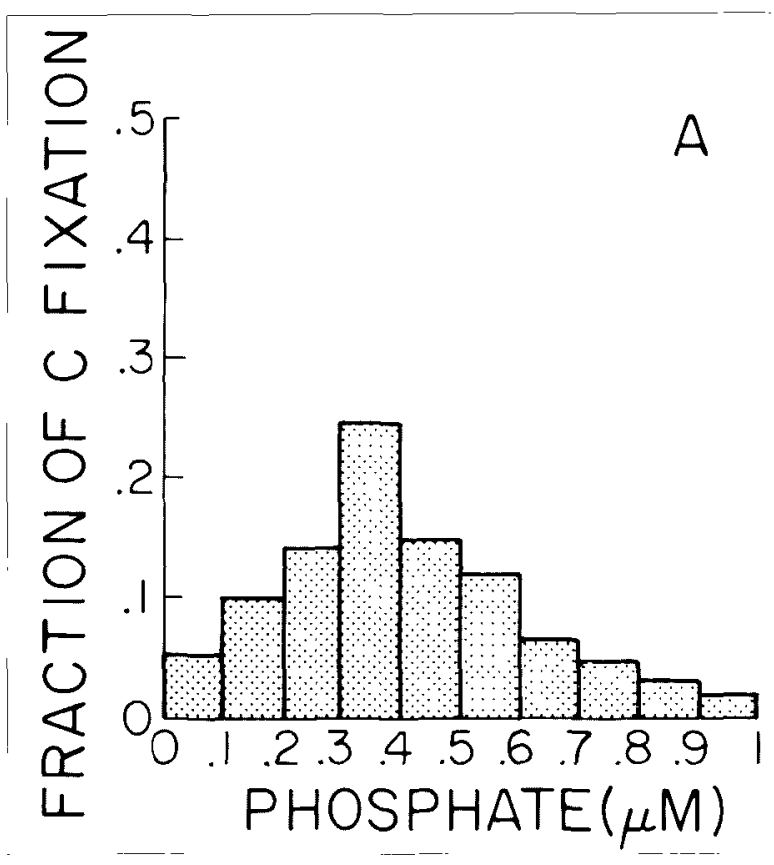

Figure 1. Primary production as function of phosphate and nitrate cencentrations. Fration of phytoplanktem production off Southern Califormia as a functon of the nutrent concentrattom of the water Note that the largest amount of phytoplankton carbon
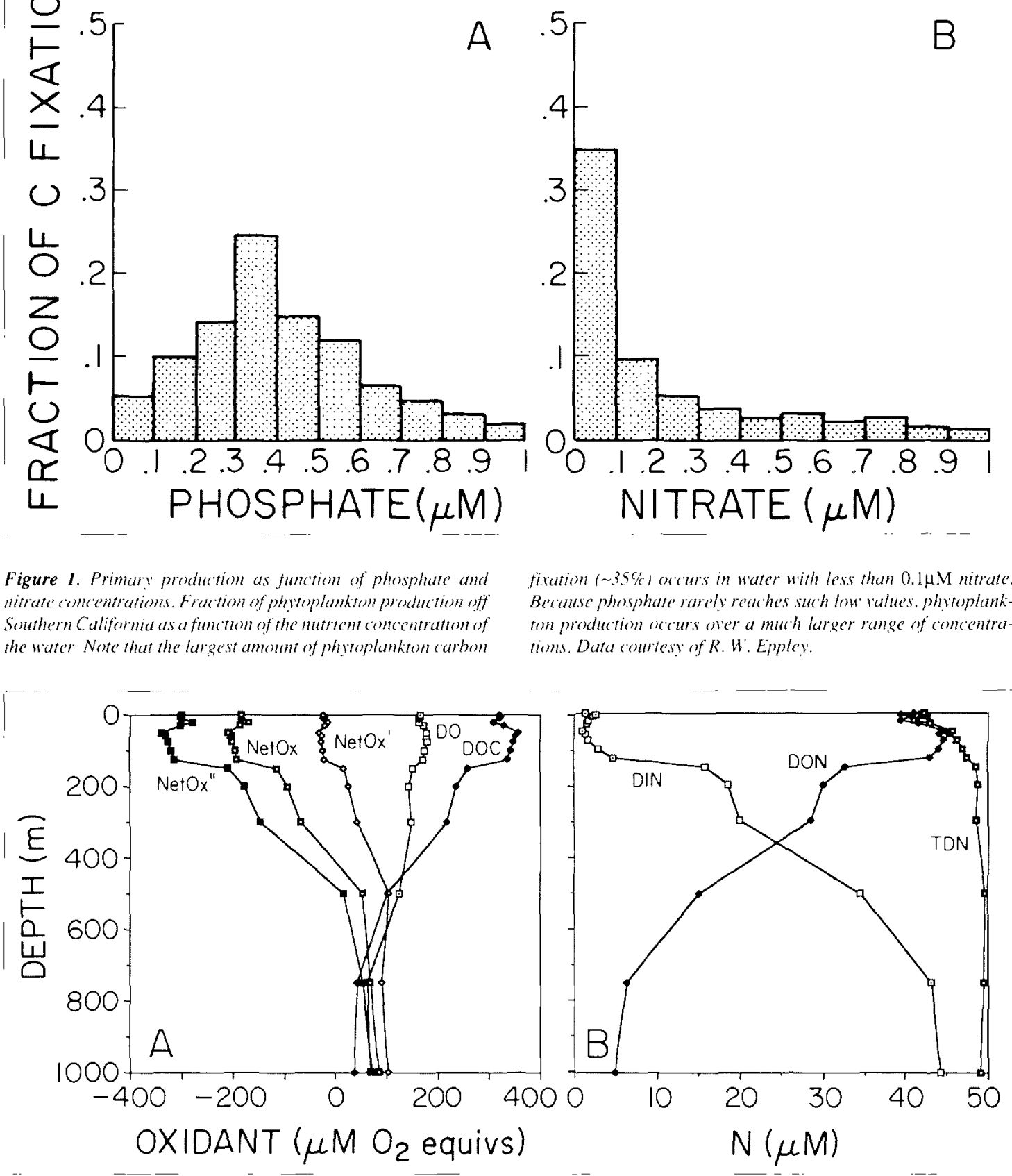

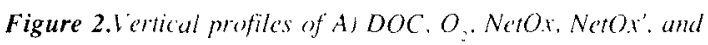
NetOr": B) dissolled morganic nitringen (DIN: essentully mtrate). DON. and TDN in the western North Pacific Datu from

this changes the concentration of a given chemical compound, it does not change total elemental concentrations. The third way is the differential transport of a chemical species, which occurs, for example, when oxygen moves from supersaturated surface waters to the atmosphere. when an organic particle falls out of a water parcel, or when a fecal pellet stops falling and begins dissolving.

Redfield (1934, 1958) argued that the nutrient concentrations in seawater are determined by the concentration ratios (the stoichiometry) of organisms in seawater. Given that the dominant dissolved

Sugimuru and Suzuki ( 1988$)$ for station at $19^{\circ} 55 \mathrm{~N} .1300^{\circ} \mathrm{E}$, here idchificed as $\mathrm{SI}$.

forms of $\mathrm{N}$ and $\mathrm{P}$ are nitrate and phosphate, then changes in their concentrations should reflect the stoichiometry of the biological matter. He found that they did.

More recent examinations of changes in elemental ratios along isopycnal surfaces resulting from remineralization have resulted in slight modifications of the Redfield values. Takahashi et al. (1985) argued that the observed $\mathrm{P}: \mathrm{N}: \mathrm{C}:-\mathrm{O}_{2}$ ratios were $1: 16: 140: 172$, although the change in $\mathrm{C}$ may reflect change in atmospheric $\mathrm{CO}$, rather than organic matter composition. Minster and Boulahdid (1987) found

The largest amount of phytoplankton carbon fixation occurs in water with less than $0.1 \mu \mathrm{M}$ nitrate. 
Particle

sedimentation is

less important than

previously thought in

determining chemical

distributions in

the ocean. values of $\mathrm{P}: \mathrm{N}:-\mathrm{O}$, on different isopycnal surfaces whose averages ranged from $1: 12.4: 115$ to $1: 9.3: 166$. The two sets of N:P values range from $12 \%$ greater to $23 \%$ smaller than the original Redfield values. Although these results show that the N:P ratios are not constant in deeper water. they also show how small the variations are. The ratios of carbon and of oxygen with other nutrient elements show much greater variation than does the ratio of $N: P$.

Similarly small differences have been noted in the stoichiometry of detrital particles in the water, as well for particles caught in sediment traps (e.g., Peng and Broecker, 1987). The recent studies have corroborated the Redfield picture of nutrient distributions determined by particle transport.

Jackson and Williams (1985) examined the nutrient budget at low concentrations, where nutrients are removed by particle production. They argued that, while the N:P ratio changed at low phosphate concentrations, a more complete accounting of total dissolved nitrogen and phosphorus (TDN and TDP) showed that the ratio of TDN and TDP was more nearly constant. That is, changes in the dominant chemical form of reduced nitrogen from nitrate to DON and phosphate to DOP masked the underlying simplicity of the system. As long as particulate matter is formed at the same nutrient concentration ratios as the dissolved matter, any biological uptake or regeneration will change the dissolved nutrient concentration in the same ratios as would mixing. The values of DON in the surface waters used to make this argument were on the order of $7 \mu \mathrm{M}$.

Recent measurements of trace metal distributions have shown that $\mathrm{Cd} . \mathrm{Zn}$ and $\mathrm{Ni}$ have distributions similar to those of the classical biological nutrients, phosphate and nitrate (see Wong. et al., 1983). The inference that trace metal distributions are determined by the transport and cycling of biological material has been generally supported by studies of trace metal concentrations on particles. This understanding has been used to study the local dynamics of the euphotic zone, where loss of particulate matter should ultimately be balanced by the movement of dissolved nutrients back into the euphotic zone. The result of this movement has been monitored by measuring the uptake of nitrate. a nutrient believed to be regenerated below the euphotic zone and to be the the predominant form of dissolved fixed nitrogen, and by expressing the result as the fraction of plant growth driven by the nitrate in a measure called new production (Dugdale and Goering, 1967).

\section{Implications of Higher of DOC and DON}

The measurement of dissolved organic compounds is an art, because the poor definition of the chemical nature of the compounds makes it difficult to prove that a given analytical technique measures even the unknown compounds not tested (Williams and Druffel, 1988). The high temperature combustion techniques of Suzuki et al. (1985) and Sugimura and Suzuki (1988) yield DOC concentrations substantially higher than those given by traditional techniques (Fig. 2. p. 29). Apparent oxygen utilization (AOU) and DOC are linearly related to each other. implying that the dominant consumption of oxygen after a water parcel leaves the surface is by the oxidation of DOC transported with it. The sum of nitrate and DON (i.e., the TDN) at Station S1 (Fig.2) is almost constant, implying that nitrate distributions in the ocean are not controlled by settling particulate matter alone, but also by oxidation of the DON carried in a parcel of water. These results suggest that particle sedimentation is less important than previously thought in determining chemical distributions in the ocean.

The higher values of DOC and DON have helped explain certain problematic measurements. For example, high concentrations of organic matter containing organic acids can explain discrepancies between alkalinities measured in seawater and those calculated from the concentration of the different titrated chemical species in the samples (Bradshaw and Brewer, 1988). Higher DOC and DON values have also been useful in explaining the vertical distributions of nutrients in models where expected particulate fluxes and regeneration have been inadequate (Toggweiler, 1988). However, the new information about DOC and DON changes our earlier understanding of other aspects of elemental cycling. The central tenet of euphotic zone nutrient cycling has been that the transport of nitrate into the euphotic zone balances the loss by particle settling. This equivalence breaks down with the introduction of substantial concentrations of DON, because the rate of introduction of new nitrogen to the euphotic zone then depends on the TDN gradient rather than just the nitrate gradient. Similarly, the loss of DON that mixes downward as nitrate mixes upward constitutes an additional sink for the nitrate. A comparison of the vertical gradients of nitrate and TDN (Fig. 3, above) shows that inclusion of DON usually decreases the magnitude of the vertical gradient. Because the diffusive flux of a substance being mixed is proportional to its gradient, the result of including the DON is a net vertical nitrogen flux that is smaller or even in the opposite direction. In the Sugimura and Suzuki (1988) data (Fig. 3), there is essentially no TDN gradient below $300 \mathrm{~m}$, even though there is a substantial gradient of dissolved inorganic nitrate (DIN) between 300 and $700 \mathrm{~m}$. Any upward flux of nitrate in this region must be balanced by a downward flux of 


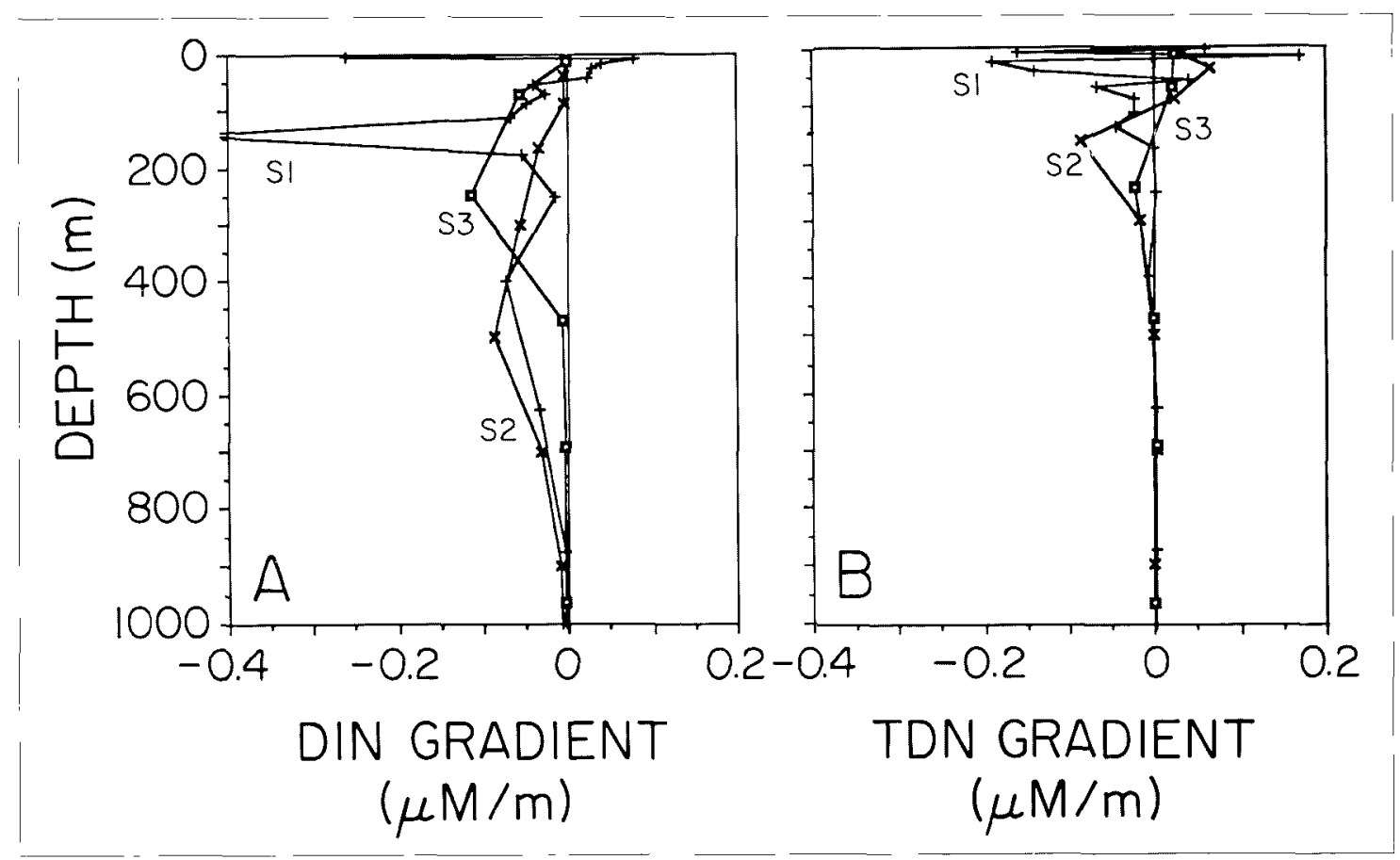

Figure 3. Vertical distribution of DIN and TDN gradicnts. Data from Sugimura and Suzuki (1988). Station SI was at $19^{\circ} 55^{\prime} \mathrm{N}$ (data indicated by $+1,130^{\circ} \mathrm{E}$; Station $\mathrm{S} 2$ was at $20^{\circ} \mathrm{N}$ (data

DON. These consequences reflect the lesser importance of particles in elemental cycling and transport. Stoichiometric Relationships.

In order to maintain fixed ratios of nutrients and trace metals, it is necessary that the total dissolved concentrations of $\mathrm{N}$ and $\mathrm{P}$ maintain the same ratio in solution and in particles. The same arguments hold for the new DON concentrations. The largest deep TDN value reported by Sugimura and Suzuki (1988) for Station S1 was only $12 \mu \mathrm{M}$ greater than the nearsurface minimum of $39 \mu \mathrm{M}$ (Fig. 2); thus, most nitrate production at that station must have occurred from the oxidation of TDN carried with a water parcel, rather than from remineralization of settling particles. Because $\mathrm{N}$ and $\mathrm{P}$ would be supplied by particle mineralization in ratios similar to the Redfield ratios, the supply of phosphate must be similarly small. Thus, it appears that the Redfield relationship between nitrate and phosphate can only be maintained if the dominant source of phosphate is the conversion of a previously unmeasured pool of total dissolved phosphate (TDP) which to be equivalent to the pool of TDN. would need to have concentrations of at least $2.5 \mu \mathrm{M}$ in surface waters. Previously reported values are on the order of $0.4 \mu \mathrm{M}$ or less (e.g., Jackson and Williams, 1985).

If the required phosphate and nitrate were being supplied by particles, their N:P ratios would have to indicated by x), $136^{\circ} 59^{\prime} E$; and Station $S 3$ was at $5^{\circ} 011^{\prime} N$. $134^{\prime} 44^{\prime} E$ (data indicated by open squares). A negative gradient indicates that the concentration decreases upward.

be quite low. Again considering Station 1 of Sugimura and Suzuki (1988) (Fig. 2), their lowest nitrate value was $0.9 \mu \mathrm{M}$ at $50 \mathrm{~m}$; the highest was $44.2 \mu \mathrm{M}$ at $1000 \mathrm{~m}$. Associated TDN values were 45.7 and $49.1 \mu \mathrm{M}$ at corresponding depths. If phosphate and nitrate were related by the Redfield ratio, phosphate concentrations must have been 0.06 and $2.76 \mu \mathrm{M}$ at those depths. If the differences between TDN and phosphate concentrations at $50 \mathrm{~m}$ and $1000 \mathrm{~m}$ were determined by transport of particulate matter between those depths, the N:P ratio of the particles would have to be 1.26. As noted earlier, particulate matter caught in traps tends to have $\mathrm{N}$ :P ratios smaller than the Redfield ratio, with values as low as 13.4 (e.g., Peng and Broecker, 1987). The N:P in sedimenting particulate matter would have to be an order of magnitude less than they appear to be in order to maintain the Redfield ratios of nitrate and phosphate. The small changes in TDN relative to phosphate argue, therefore, for a large, previously unmeasured TDP pool.

Similar arguments can be made for other elements that have fairly constant stoichiometric relationships with nitrate and phosphate when dissolved and with $\mathrm{N}$ and $\mathrm{P}$ when in particles. Thus, there may also exist large, previously unmeasured concentrations of the trace metals $\mathrm{Cd}, \mathrm{Ni}$ and $\mathrm{Zn}$. Presumably, these might also be in a chemically resistant but biologically
The result

of including the DON is a net vertical nitrogen flux that is smaller or even in the opposite direction. 
The small

changes in TDN

relative to phosphate

argue for a large,

previously

unmeasured

TDP pool.

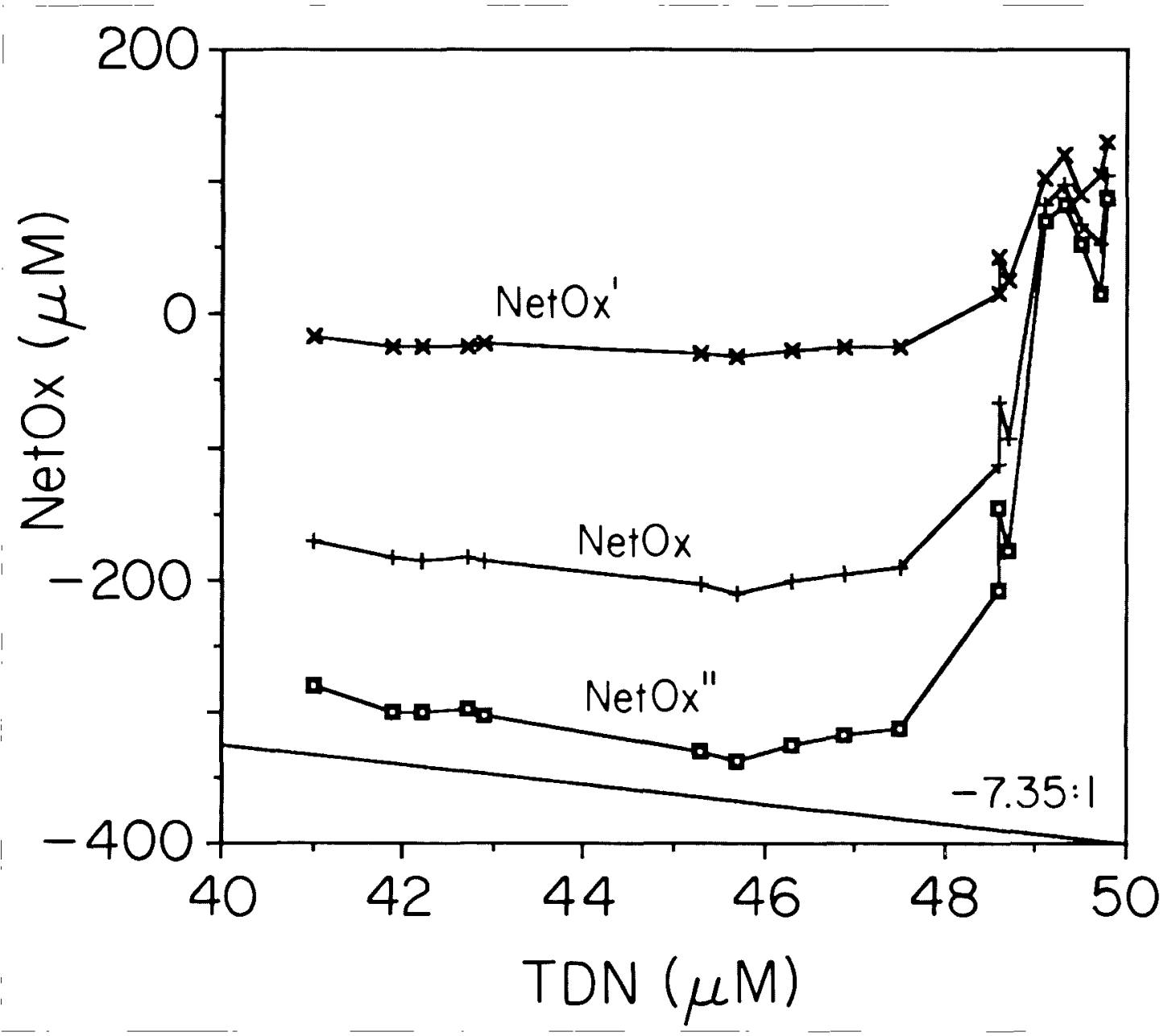

Figure 4. NetOx, + NetO $x^{\prime}$ and NetOr" see text for definitions) as functions of TDN. Values calculated for data from Sugimara and Suzuks (1988) for Stution SI. as in Fig. 2. In a ene dimensional swstem. TDN and NetOx would change becaltse' of mating and particle formation or dissoluton, and the slope of the NetOX

labile form related to the previously unmeasured organic carbon and nitrogen.

Particle Sedimentation and Oxidant Balances.

When considering the role of dissolved organic matter in oxidant balances, it is important to include the oxygen consumed in oxidizing ammonia and DON to nitrate. Jackson and Williams (1988) have defined a quantity called NetOx that does not change when organic matter is formed or consumed but does change when particles leave or arrive in a water parcel:

$$
\mathrm{NetOx}=\left[\mathrm{O}_{2}\right]+1.25\left[\mathrm{NO}_{3}^{-}\right]-0.75\left([\mathrm{DON}]+\left[\mathrm{NH}_{3}\right]\right)-\lambda[\mathrm{DOC}]
$$

NetOx also changes when there is exchange of oxygen or other constituent quantities across a boundary: e.g., an oxygen gain from the atmosphere or oxygen loss at a sedimentary interface. Just as alka- curves weruld be -7.35 for a $C$ N ratio of $0.67: 1$ in particulate matter (Jackson and Williams. 1988 ). In water deeper than abent $100 \mathrm{~m}$, none of the curves has this shope, which indicates a de'gre' of decoupling of the TDN and NetOr profiles at depth.

linity is insensitive to $\mathrm{pH}$ or $\mathrm{CO}$, changes but is sensitive to carbonate precipitation. NetOx is unaffected by production of organic matter that does not move oxidant (e.g.. $\mathrm{O}_{2}$ ) or reductant (organic matter) out of a water parcel: however. it is affected by the loss of organic matter by a particle sinking out of the surface waters and by its subsequent dissolution deeper in the water column. This sensitivity to only the loss or gain of the particles and exchange across boundaries makes NetOx a useful quantity for analysis of the distributions of dissolved organics. In this context, DON or DOC refers to the particulate as well as the dissolved compounds present in a sample. Particulate organic compounds usually are a small fraction of the organic matter.

The NetOx concept is based on an electron balance. In the above equation the parameter $\lambda$ is the average redox state of the $\mathrm{C}$, in $\mathrm{O}$, equivalents. The 
redox state of DON is assumed to be the same as that of the amine group and of ammonia, -3 . The oxidation of each nitrogen atom to nitrate consumes $2 \mathrm{O}_{2}$. Nitrogen in organic compounds is normally in this state. When each $\mathrm{C}$ in $\mathrm{DOC}$ is in the redox state of 0 , the redox parameter $\lambda=1$. However, if oceanic DOC is highly oxidized but still polymeric, it could have a redox state of +2 , in which case $\lambda=0.5$ because 0.5 $\mathrm{O}$, molecule is required to oxidize each $\mathrm{C}$. The modified NetOx with $\lambda=0.5$ is called NetOx'. In cases where organic matter is more reduced, as suggested by the results of Takahashi et al. (1985), the appropriate $\lambda=1.36$ and the result is NetOx". The general form of NetOx provides a useful tool to distinguish between oxygen production and consumption mediated by organic matter that travels with a water parcel, such as DOC and DON, and that which travels differently by formation. sinking and degradation elsewhere.

Profiles of NetOx, NetOx' and NetOx" can be calculated from the DOC. DON. $\mathrm{NO}_{3}$ and $\mathrm{O}_{2}$ data presented by Sugimura and Suzuki (1988). The vertical distribution of NetOx at their Station SI decreases slightly to a minimum of $-204 \mu \mathrm{M}$ at $50 \mathrm{~m}$ depth, and then increases with depth, reaching a value of $84 \mu \mathrm{M}$ at $1000 \mathrm{~m}$ (Fig. 2). The TDN is a minimum of $41 \mu \mathrm{M}$ at $20 \mathrm{~m}$ and it increases to $49.7 \mu \mathrm{M}$ at $500 \mathrm{~m}$.

The one dimensional (vertical) model traditionally is used to explain vertical concentration distributions (e.g., Martin et al., 1987). In such a model system, NetOx and TDN should both be changed by particle formation and degradation but not by oxidation of DON or DOC. If the vertical distribution of NetOx and TDN were determined by the formation and dissolution of particles having $C$ in a redox state of 0 and a $C: N$ ratio of 6.6 , then changes in the two should be related by a Redfield-like ratio of -7.35 . and the NetOx-vs-TDN curve therefore should have a slope of -7.35 . However, for depths greater than about $100 \mathrm{~m}$, the NetOx curves widely depart from this slope (Fig. 4, p. 32). which indicates a deepwater decoupling of the NetOx-TDN relationship. For example, the TDN changes from 41 to $48 \mu \mathrm{M}$ in the surface layer, a region where there is virtually no change in NetOx, but the NetOx changes by almost $300 \mu \mathrm{M}$ in a deeper region where there is only about $2 \mu \mathrm{M}$ change in TDN. Furthermore, the decoupling occurs regardless of the assumed oxidation state of the DOC, as shown by the NetOx' and NetOx" curves in Fig. 4. Because particle formation, transport and dissolution should couple the two, a one-dimensional description of this system fails in deep water. However, the fact that the largest changes in TDN occur in the upper $100 \mathrm{~m}$ (Fig. 2), in a region where the NetOx:TDN ratios are consistent with a Redfield ratio line, indicates that a one-dimensional model may be useful for small vertical scales. A more complete understanding of the dynamics of elemental cycling and the relative roles of dissolved and sedimenting organic fluxes will require sufficient information about their distributions to build a threedimensional understanding.

Finally, if the new, higher values of DON and DOC are correct, then there should be similar corrections to the measured concentrations of other elements whose concentrations are affected by organism growth and decay. Such elements include P, Cd, $\mathrm{Ni}$ and Zn. Finding such higher concentrations would constitute an independent verification of the new values of the DOC and DON.

Acknowledgements: This work was supported by U.S. Department of Energy Grant DE- FG05-85-ER60341. P. Williams and B. Ward provided helpful criticism of the manuscript.

\section{References}

Bradshaw, A. L. and P. G. Brewer, 1988: High precision measurements of alkalinity and total carbon dioxide in seawater by potentiometric titration. 1. Presence of unknown protolyte(s)? Mar. Chem. 23, 69-86.

Craig. H.. W. S. Broceker and D. Spencer, 1981: Geosecs Pacific Expeditum. Vol. A. Sectom and profiles. U. S. Government Printing Office, Washington, D.C., $251 \mathrm{pp}$.

Dugdale, R. C. and J. J. Goering. 1967: Uptake of new and regenerated forms of nitrogen in primary productivity. Limnol. Oceunogr. 12, 196-206.

Jackson. G. A. and P. M. Williams, 1985: Importance of dissolved organic nitrogen and phosphorus to biological nutrient cycling. Deep-Seu Res. 32. 223-235.

Martin. J. H., G. A. Knauer. D. M. Karl and W. M. Broenkow, 1987: VERTEX: Carbon cycling in the northeast Pacific. Déep-Sea Res. 34, 267-285.

Munster. J.-F. and M. Boulahdid, 1987: Redfield ratios along isopycnal surfaces Qa complementary study. Deep-Sea Re's. 34. 1981-2003.

Peng. T. $-\mathrm{H}$, and W. S. Broecker, 1987: C/P ratios in marine detritus. Global Biogenchemical Cycles I. 155-161.

Redfield. A. C., 1934: On the proportions of organic derivations in sea water and their relation to the composition of plankton. In : Jumes Johnstone Memorial Lolume. Liverpool, pp. 177192.

Redfield, A. C.. 1958: The hiological control of chemical factors in the environment. American Scientist 46, 205-221.

Sugimura, $Y$. and Y. Suzuki, 1988: A high temperature catalytic oxidation method for nonvolatile dissolved organic carbon in seawater by direct injection of liquid samples. $\mathrm{Mar}$. Chem. 24. 105-131.

Suzuki, Y.. T. Sugimura and T. Itoh. 1985: A catalytic oxidation method for the determination of total nitrogen dissolved in seawater. Mar. Chem. 16, 83-97.

Takahashi, T., W. S. Broecker and S. Langer, 1985: Redfield ratio based on chemical data from isopycnal surfaces. J. Geophys. Res $90,6907-6924$.

Toggweiler. J. R., 1988: Is the downward dissolved organic matter flux important in carbon transport? To appear in: Productivity of the Ocean: Present and Past (Dahlem Konferenze'n), (Berger. W. H., V. S. Smetacek, and G. Wefer. eds.). Wiley, Chichester, (in press).

Williams, P. M. and E. R. M. Druffel, 1988: Dissolved organic matter in the ocean: Comments on a controversy. Oceanogr. Mag., 111). 14-17.

Wong. C.S., E. Boyle. K. W. Bruland. J. D. Burton and E. D. Goldberg (eds.), 1983:Trace Metals in the Sea. Plenum. New York. $920 \mathrm{pp}$.
A one-

dimensional

description of this

system fails in

deep water. 